\title{
RELATIONSHIP BETWEEN BREASTFEEDING PRACTICES AND NUTRITIONAL STATUS OF CHILDREN AGED 0-24 M ONTHS IN NAIROBI, KENYA
}

Muchina EN ${ }^{1 *}$ and PM Waithaka ${ }^{2}$

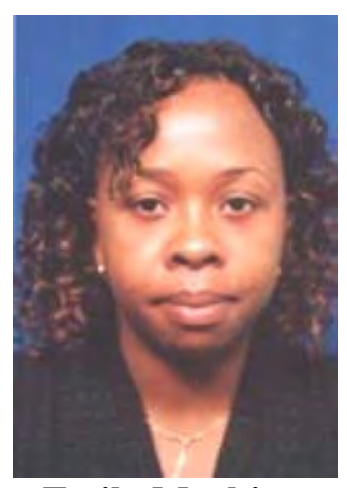

Emily M uchina

*Corresponding author: emillienm@yahoo.co.uk

${ }^{{ }^{*}}$ Lecturer, Nursing Department, Kenya Methodist University P.O. Box 267, Meru, Kenya.

${ }^{2}$ Lecturer, School of Nursing Sciences University of Nairobi. P.O Box 270 (00202 $\mathrm{KNH})$ Nairobi. 


1.JPIDNELINE

\section{ABSTRACT}

Breast milk has a major impact on child health, growth and development. Infants should exclusively breastfeed (EBF) for six months, then, nutritionally adequate and safe complementary foods should be introduced. This study's aim was to determine the breast feeding practices (initiating breastfeeding within one hour of child birth, exclusive breastfeeding for six months, no bottle feeding, and breastfeeding until or beyond two years and on demand breastfeeding) of mothers in Nairobi, and nutritional status of their children aged zero to twenty four months. A descriptive cross-sectional survey was used in the maternal child health $(\mathrm{MCH})$ clinics in four selected Nairobi City Council health centres. A dyad (pair) of mother and her 0-24 month old child were targeted. The dyads were systematically selected based on the nth mother (where $\mathrm{n}$ was a fraction of desired sample size per actual number of mothers present in the clinic that day). A structured questionnaire was administered, which focused on maternal socio-demographic profiles and breastfeeding practices. Anthropometric assessments were conducted on the children. A total of 418 dyads were analysed, $99.0 \%$ of the mothers had breast fed, but only $12.6 \%$ children had been exclusively breastfed for the first six months. Only $34.0 \%$ of children aged less than six months were still exclusively breastfeeding, the rest were on complementary feeds. More than three quarters of the mothers had initiated breastfeeding within one hour of child birth, were not using bottles to feed their child, were breastfeeding on demand and had not weaned their child. On nutritional status assessment of children, $10.6 \%$ were stunted, $6.2 \%$ underweight and $2.1 \%$ wasted. There was a significant association between delay in time of breastfeeding initiation after childbirth and stunting P $₫ 0.05$ (odds ratio 2), discontinuation of breastfeeding and underweight $\mathrm{P} \unlhd 0.05$ (odds ratio 4.5), as well as weaning less than six months and underweight $P \unlhd 0.05$ (odds ratio 2.5). There was no significant association between breastfeeding practices and wasting. Children on bottle feeding and those who had discontinued breastfeeding were likely to be wasted (odds ratio 1.6).However, these associations do not control for age, and both underweight and wasting are related to age. A majority of mothers were compliant with the recommended breastfeeding practices. Complementary feeding was introduced too early in life in several cases. Health care workers should emphasise the importance of exclusive breastfeeding for the first six months and the dangers of early complementary feeding.

Key words: Exclusive Breast feeding, Nutritional status 


IJFININANE

\section{INTRODUCTION}

Breast milk is a natural resource that has a major impact on child's health, growth and development and it is recommended for at least the first two years of a child's life [1]. Breast milk contains the nutrients that a baby needs and in the right quantity. The nutrients are quickly and easily digested [2].

Early initiation of breastfeeding increases chances of breastfeeding success besides, it generally lengthens the duration of breastfeeding and immediately after birth assists in uterus involution thus preventing postpartum haemorrhage [3]. It is recommended that infants should be exclusively breastfed for the first six months of life. Thereafter, nutritionally adequate and safe complementary foods should be introduced while breastfeeding continues for at least two years [2]. No other feeds or formula milk should be given till the baby is six months old. Mothers should avoid use of pacifiers and bottle-feeding with artificial teats since they affect dental development and are a source of infections that cause diarrhoea among the infants [4]. On demand breastfeeding (when the child requests) and allowing to feed until satiated, is encouraged in order for the infant to regulate their intake according to their needs hence be able to express their appetite [5].

Decline in breastfeeding is associated with women's involvement in work force as well as lack of knowledge on the benefits of the practice and management of lactation problems. Bottle-feeding is thus perceived as the modern way and breastfeeding as old fashioned and inconvenient [6]. A WHO/UNICEF paper stated that women need advice about how often to feed their babies, about giving other fluids and solids, common problems associated with breastfeeding such as sore nipples, sore breasts, inadequate production of milk, production of too much milk and leaking breasts among others [1].

Breastfeeding is a pivotal factor between life and death for the vast majority of children in developing countries. Less than $35.0 \%$ of infants worldwide are exclusively breastfed during the first six months of life [1].This low adoption of appropriate breastfeeding practices has been found in developing countries especially in Africa. Kenya is no exception, in that in spite of breastfeeding being universal only $14.0 \%$ infants less than six months are exclusively breastfed. Thus complementary feeds are introduced quite early in a child's life and by six months three quarters have not been given complementary feeds while $27.0 \%$ under six months are bottle fed [1]. In Nairobi, more than one-quarter of children under six months are bottle fed, only $55.1 \%$ initiate breastfeeding within one hour after childbirth, while $51.3 \%$ give prelacteal feeds. The median duration of exclusive breastfeeding and total breastfeeding are 0.5 and 16.7 months, respectively; much lower than the recommended duration [3].

Globally an estimated 1.3 million lives are lost each year due to inadequate exclusive breastfeeding and another 600 thousand from lack of continuation of breastfeeding with proper complementary feeding [1]. In addition, improper infant and young child

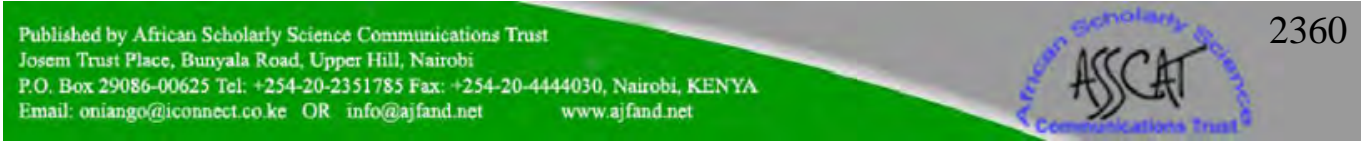


feeding cause one third of malnutrition. Studies have shown that inappropriate breastfeeding practices are associated with severe malnutrition in the under five children, lack any advantage in terms of weight gain and are associated with growth faltering [7]. Malnutrition has significant health and economic consequences, which includes increased risk of death, illness and lower cognitive development among others. In Kenya $30.3 \%$ of children aged less than five years are stunted, 5.6\% are wasted and $20.0 \%$ are underweight while in Nairobi $18.7 \%$ are stunted, $4.5 \%$ wasted and $6.3 \%$ underweight [3]. About $33.0 \%$ of all deaths before the age of five years in Kenya are related to malnutrition [8].

The government has developed policies on infant and young children feeding practices based on the UNICEF baby friendly initiative, and supports the WHO codes for marketing breast milk substitutes with an aim of promoting, protecting and supporting breastfeeding. However, studies have shown that mothers are lacking adequate knowledge on breastfeeding [9]. Understaffing of most public health facilities has a detrimental effect on quality time spent and the frequency of nutrition education sessions. Inadequate maternal knowledge about feeding practices is often a greater determinant of malnutrition than lack of food.

Children continue to suffer from malnutrition and its related complications despite efforts by policy makers and health care service providers. There seems to be a gap between what should be happening and what is actually happening in relation to maternal breast feeding practices that needs to be addressed. The objective of this study was to establish breastfeeding practices among 0-24 month children and the association of these practices to the nutrition status of the children.

\section{RESEARCH METHOD}

\section{Study area}

A cross-sectional descriptive study was conducted in Nairobi Kenya, which is a cosmopolitan city with inhabitants from various socio-economic backgrounds [10]. The study was conducted in the Nairobi City Council health centres namely: Kangemi, Langata, Riruta and Mathare. These centres are mainly utilized by the people of low social economic status.

\section{Study population}

The study population comprised a dyad of mother and child (0-24 months old) attending four $\mathrm{MCH}$ clinics operated by the Nairobi city council. The age category of infants and children was chosen on basis of recommendations of the maximum total breastfeeding period of 24 months and beyond [1]. The mothers were selected as the source of information since they are the first in line as far as breastfeeding is concerned.

\section{Sampling}

Four health centres based on the highest clients load and geographical distribution were selected. Probability proportionate sampling was used to determine the number

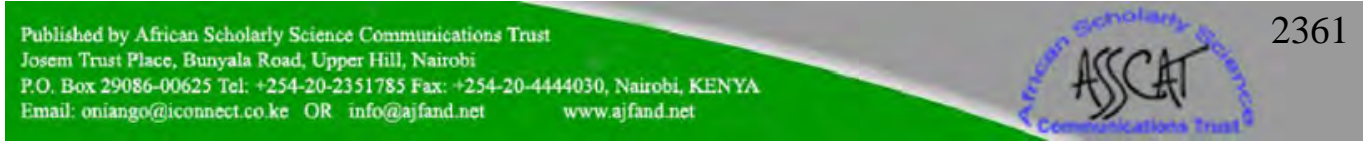


of mothers to be studied from each facility. The average monthly attendance in the $\mathrm{MCH}$ (the clients are mainly mothers with their children less than five years) in the four health centres, $\mathrm{N}=25,380$, the minimum required sample size, $\mathrm{n}=376$ (based on Fisher's formula on sample size calculation) hence a proportionate constant $K=n / N$ $=0.015$. The constant $\mathrm{K}(0.015)$ was applied to determine the sample size for each clinic by multiplying the average number of mothers who attend the selected clinic per moth by the constant. For the purpose of correcting for any spoilt or damaged questionnaires an extra $10 \%$ mothers were sampled in each clinic, hence the actual number of mother sampled was 418 .

As the mothers arrived, growth and monitoring and immunization cards were obtained to ascertain the child's age. Then a dyad of mother and child who met the selection criteria was identified and targeted for inclusion in the study. All those targeted were interviewed until the predetermined proportionate number for the day was achieved (the proportionate number for the day was determined by dividing the sample size for the clinic by the number of days for data collection).

\section{Study tools}

Four study tools were utilised. These were: a structured questionnaire; a Salter scale in kilograms and weighing to accuracy of 0.1kilograms; a measuring length board graduated in centimetres, with a sliding foot piece was used to measure the length of the 0-24 months children; and child's national growth and monitoring chart was used to establish the child's date of birth.

Data collection was conducted over a period of six weeks by trained undergraduate students on attachment at the selected health facilities.

\section{Data analysis}

Anthropometric data (age, weight and length measurements) were entered in the SPSS package then exported to the Epi-nut package where data was cleaned and Z-scores for the indicators of nutrition status obtained. Three standard nutritional indicators used were weight-for-height (Wasting), weight-for-age (Underweight) and heightfor-age (Stunting), these were expressed in standard deviations (Z-scores) from the mean of the international reference population according to the National Centre for Health Statistics (NCHS) [11]. Deviations of the indicators below -2.01 to -3 standard deviation indicated that the children were moderately malnourished, deviations below -3 indicated severely malnourished children while a deviation of -2 to 1.99 reflected well-nourished children, beyond z-scores of 2 indicated over nutrition.

Chi-square analysis was used to determine the associations between variables at a significance level of $P \unlhd \mathbf{} \unlhd 5$. Odds ratio was calculated to estimate the relative risk.

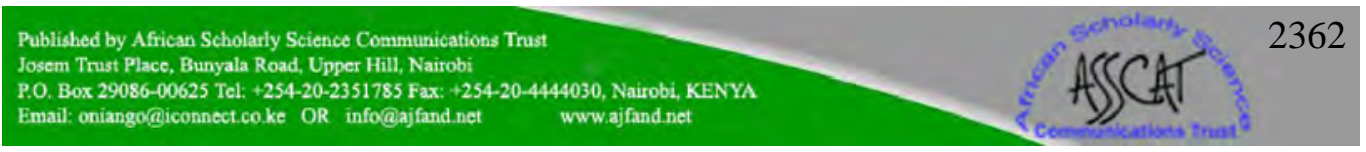




AJFININANE

\section{STUDY RESULTS}

\section{Socio-demographic profile}

A majority $91.1 \%$ of the mothers were married, $98.1 \%$ were Christians, $93.7 \%$ had attained primary and secondary levels of education and $62.7 \%$ were housewives while $21.3 \%$ were self employed. Approximately $87.0 \%$ of the mothers had three or less children. The minimum and maximum monthly incomes were between Ksh.500 and Ksh.37, 000, respectively. The mean income was Ksh. 5, 499, ( \pm s.d) (95\% CI: 5,180$5,819)$. A majority of the interviewed mothers $(67.2 \%)$ were in the age group $21-30$ years with a mean age of 24.4 years. The minimum age was 17 years while the maximum was 39 years.

The males made up to $51.9 \%$ of all the children in the study; the rest $48.1 \%$ were females. About $68.2 \%$ of the children had been born in a hospital set-up while $31.8 \%$ were born at home. A majority $89.3 \%$ were aged one year and less and only $9.8 \%$ were more than a year old. The mean age of children was 5.8 months $( \pm$ s.d) $(95 \%$ CI: $5.4-6.2)$.

\section{Feeding modes of children}

Two thirds of those aged less than 4 months had been introduced to complementary feeds and only $39.0 \%$ were exclusively breast feeding (EBF). Virtually all the children $(97.8 \%)$ were on breast milk regardless of the age group. Discontinuation of breastfeeding increased gradually with age. The proportion of bottle fed children was highest among the 0-4 months old children (31.1\%) and lowest among the 13-24 months old (7.3\%). There was no difference in mode of feeding between the male and female children refer to Table 1.

\section{M aternal breastfeeding practices}

Virtually all mothers $99 \%$ ) had breast fed their children. Of those who breast fed a majority $(61.1 \%)$ were reported to have initiated breastfeeding within one hour of child birth. The main reasons given for failure to breast feed within one hour, were insufficient milk production $(28.5 \%)$, inability of the infant to suck at the breast $(18.6 \%)$ and maternal exhaustion.

A majority (90.6\%) of the mothers practiced breastfeeding on demand. Also $79.0 \%$ (326) did not give any prelacteal feeds to their newborn. Of the $21.0 \%$ who gave prelacteal feeds, $44.6 \%$ was sugary/ glucose water, $21.7 \%$ plain water, $18.1 \%$ formula milk, $9.6 \%$ sugary salty water, and $6.0 \%$ other types of milk and gripe water.

Only $12.6 \%$ of the children who were more than six months of age had had EBF for the first six months and 34\% of children less than six months were still EBF at the time of the study. The rest $66 \%$ had been introduced to complementary feeding. The mean age of complementary feeds introduction was 2.9 months (95\% CI: 2.7-3.1). The mothers who were practicing EBF at the time of data collection had the intention of introducing complementary feeds at the mean age of 4.4 months at (95\% CI: 4.0 $4.8)$.

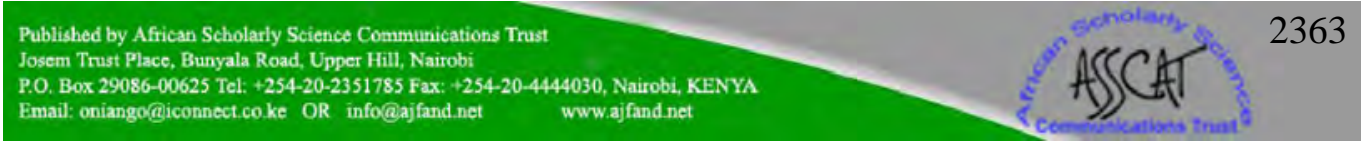


Virtually all mothers $(97.8 \%)$ were still breastfeeding at the time of the interview. The reasons given for discontinuation of breastfeeding were inadequate breast milk to meet child's needs $(44.4 \%)$, child refusal to breastfeed $(33.3 \%)$ and maternal illness $(22.2 \%)$.

Most mothers complied with most of the recommended breastfeeding practices with the exception of EBF for their child for the first six months (see Table 2).

\section{Nutrition Status: Distribution of the Children by Nutrition Status}

No child was found to be oedematous on examination. A majority of the children displayed good nutritional status in that $2.2 \%$ had acute malnutrition, $6.2 \%$ were underweight while $10.6 \%$ had chronic malnutrition, (see Table 3).

The various age groups of children in the study displayed different nutritional status as among the different age groups (Figure 1) Stunting was more prevalent among children more than 7 months to 12 months old which was almost three times that observed among children aged 0-6 months, but decreased slightly by age 13-24 months. Underweight increased with age and was more prevalent among children aged 13 to 24 months of age. Wasting was highest among children aged 13-24 years old. In general children in the age group of zero to six months were less malnourished as compared to rest of the age groups. It should be noted almost all the mothers indicated having introduced complementary feeds to their children by age of 9 months, this practice may be contributing to the nutritional outcomes trends observed in the study as illustrated in Figure 1.

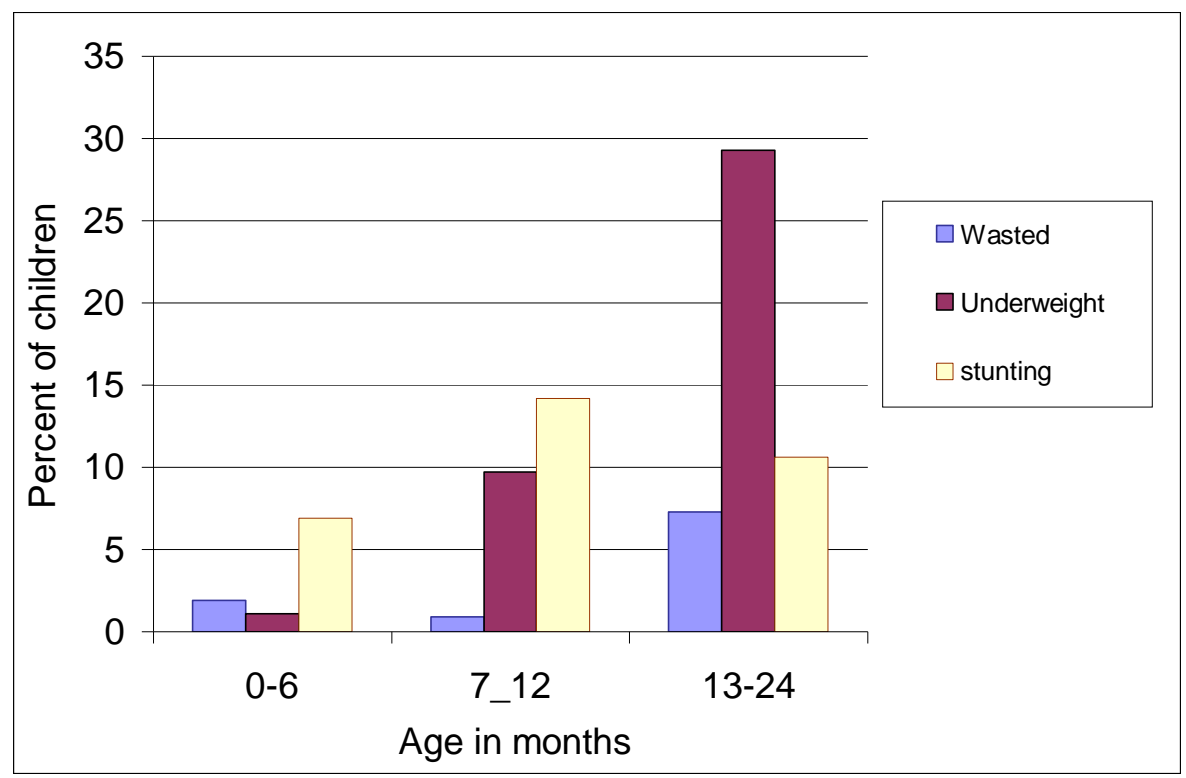

Figure 1: Trends between the nutritional outcomes and age

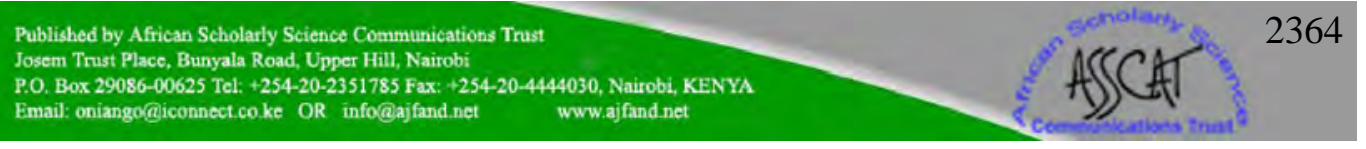




1.JPid DNELE

Association between breastfeeding practices and the nutrition status of children In comparison to children who were continuing breastfeeding those who had discontinued breastfeeding were one and half times likely not to suffer from wasting. Further, children who were bottle-feeding were one and half times likely be wasted as compared to those who were breast-feeding. There was however, no statistical significance association between each of the commended breastfeeding practices and wasting (see Table 4).

There was a significant association between continuing breastfeeding for a child less than 24 months and underweight (P $\$ 0.05)$. Children who had discontinued breastfeeding were more than four times likely to be underweight compared to those continuing breastfeeding. In addition, children who had not been EBF for six months were more than twice as likely to be underweight than those who had EBF (see Table 5). However, note these relationships do not control for age, and wasting and underweight that are age-dependent.

A significant association between time of initiation of breastfeeding after childbirth and stunting was established (P $₫ 0.05)$. It was observed that children who were breastfed after one hour of birth were twice as likely to be stunted as compared to those who breastfed within one hour of birth (see Table 6).

\section{DISCUSSION}

\section{B reastfeeding practices}

\section{Prevalence of breastfeeding}

Generally the prevalence of breastfeeding was high (99\%). The high breastfeeding prevalence compares with previous community based studies in Nairobi where the prevalence of breastfeeding was $96.2 \%$ and $96 \%$ respectively [3, 12]. In KanartakaIndia, the percentage of children who had ever been breastfed was also high $97 \%$ [13]. This contrasts with findings in a developed country, Kentucky-USA where only $49.2 \%$ of children were ever breastfed [14].

Virtually every mother practiced on demand breastfeeding probably because most were constantly with their children since a majority were reported to be housewives or self- employed. On demand breastfeeding as opposed to scheduled feeding allows the child to regulate their intake according to their body needs, thus expressing their appetite fully [5].

Most children were still breastfeeding at the time of the study and their mothers intended to continue breastfeeding them for at least twenty-four months of age. This was commendable practice since it indicated that mothers embraced breastfeeding due to the knowledge of its importance to their child. Early discontinuation of breastfeeding was mainly due to insufficiency of milk to meet the child's nutritional

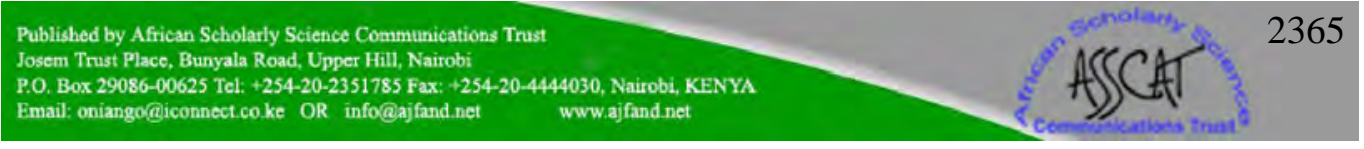




1.JPIDNELINE

needs. This relates to findings by Marandi, in which a higher proportion of mothers $(39 \%)$ gave a similar reason for early discontinuation of breastfeeding [15].

Initiation of breastfeeding after child birth

Women are encouraged to initiate breastfeeding within one hour after birth; this is with the exception of HIV positive mothers who do not wish to breastfeed. Early initiation of breastfeeding increases chances of breastfeeding successfully, generally lengthens the duration of breastfeeding and immediately after birth assists in uterus involution, thus prevent post partum haemorrhage [3].

Two thirds of mothers initiated breastfeeding within one hour of childbirth; the proportion was slightly higher than that of $55.1 \%$ in Nairobi and $52.3 \%$ nationally [3]. The slight difference could be attributed to the different study settings, since CBS study was carried out at the community set-up while this study was at a health facility setting. On the contrary, in Kanartaka-India only 3 infants $(0.3 \%)$ were offered breastfeeding within 1 hour after delivery and most infants $90.9 \%$ begun breastfeeding 72 hours post-delivery [13]. Similarly, in Teheran-Iran the average period between delivery and initiation of breastfeeding was 42.5 hours [15].

Reasons for late initiation of breastfeeding after childbirth such as inability of the child to suck, insufficient or no breast milk production among others revealed lack of awareness of the rationale behind early initiation of breastfeeding.

\section{Prelacteal feeds}

Generally prelacteal feeds are known to interfere with early attachment of the child to the breast. Over three quarters of the mothers did not give any form of prelacteal feeds to their index child. These findings differ from a community based study by CBS [3] in which a significantly higher proportion of children in Nairobi $(51.3 \%)$ and $(65 \%)$ nationally were given prelacteal feeds while in Kanartaka- India all infants received prelacteal feeds [13].

\section{Bottle feeding}

Bottle feeding is discouraged because improper sanitation and formula preparation with bottle feeding can introduce pathogens to the infant, putting the child at a greater risk of illness and malnutrition [16]. Most mothers used safe modes of giving fluids to the child such as cups, spoon and bowls/plates. Similar findings by Torimiro et al., in Nigeria indicated that $78.3 \%$ of the mothers were not using feeding bottles [17]. In a low-income peri-urban community, Shamin established that out of 105 mothers 102 were using feeding bottles with teats for infants with or without breastfeeding, this was a very high prevalence of bottle-feeding compared to this study [18].

\section{Exclusive breastfeeding}

For optimal growth it is recommended that infants be exclusively breastfed for the first six months of life. Overall, only a tenth of the children had been exclusively breastfed for the first six months of life and only a third of infants less than six months were breastfeeding exclusively at the time of data collection. For the latter children, it

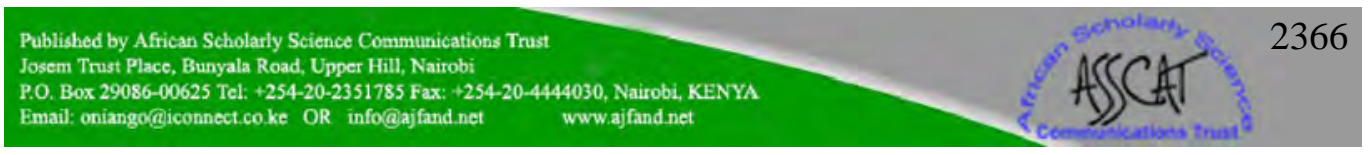




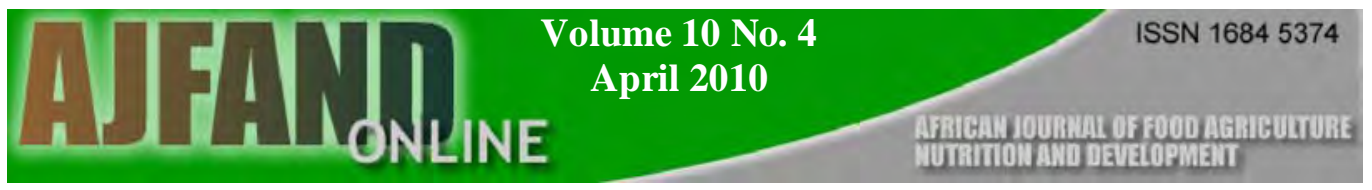

was noted that most of their mothers had a strong intention of exclusively breastfeeding for up to six months. In practice however, by the fourth month a majority $(63.1 \%)$ of children had started receiving complementary feeds. This indicates that mothers have good intentions of exclusively breastfeeding for about six months but, introduce complementary feeds earlier than the intended age. This raises questions as to whether the standard of six months, is unrealistic thus unattainable for this community whose malnutrition rates were also low.

These findings compare with numerous other studies that have documented that early introduction of complementary feeds before the age of six months is a persistent negative practice regardless of the efforts put forward in improving the trend. Nationally, in Kenya only $14 \%$ of infants were exclusively breastfed up to the age of six months, while the remaining majority had been introduced on complementary feeds/fluids [8]. A two-year prospective study in Nairobi's, low-income region, Kangemi established that by one month $75 \%$ infants had received complementary fluids and feeds and by the fourth month $94 \%$ had received complementary feed [19]. Besides, in a comparative study between a World Vision project and non-project areas in Makueni district indicated that $37.5 \%$ and $68.3 \%$ in the project and non-project areas respectively, introduced complementary feeds within the first three months [20]. Similarly, a study in the Central region of South Africa, indicated that exclusive breastfeeding during the first three months was uncommon as mothers tended to introduce complementary feeds at an early age, with $56 \%$ of the infants receiving some form of supplement by the end of the first month [21].

Nutrition status of the children

Most of the children in the study were below the age of one year, an indication that most mothers did not take their children for growth monitoring after completion of immunizations and vitamin A supplementation.

Acute malnutrition as measured by weight- for -height (WFH) was virtually absent among the study children probably because almost all children were still breastfeeding on demand prior to and during the time of study. This is also in line with the low national level of wasting that stands at 5.6\% nationally and in Nairobi $4.4 \%$ for underfive years old children [8]. Wasting was highest in children aged 13-24 months, and was also in line with findings by the CBS where wasting was highest in the 12-23 months age category [3].

Chronic malnutrition affected $10.6 \%$ of the children; this was well below the national and provincial level of stunting of $30.3 \%$ and $18.7 \%$, respectively. The level of underweight $(6.2 \%)$ was also lower than the national level of $19.9 \%$ but at the same level with that of the province $(6.3 \%)$. Stunting was more prevalent among children 13 to 24 months but underweight was more prevalent among 7-12 months old children. This compares with findings for a study done in Thika-Kenya where stunting was more prevalent among the $13-24$ month's old children and the same pattern was observed for underweight [22]. Similarly, Stunting was found to be highest (43\%) in the 12-23 months old children and the same trend with underweight (27\%) [3]. In

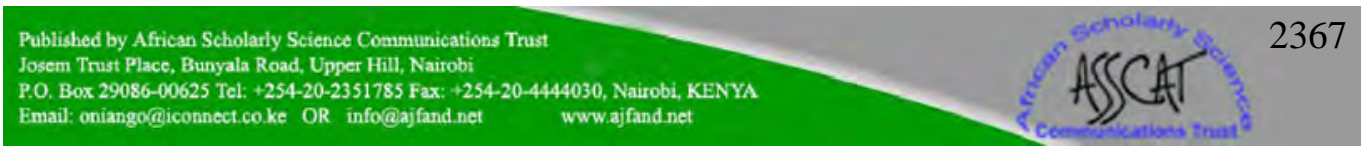




1.JPididelNe

Chandigarh-India, proportions of underweight (45.5\%) and stunting $(81.8 \%)$ were found maximum among children aged 13-24 months [23].

Relationship between breastfeeding practices and nutrition status of the children The risk of being underweight was higher among children who had discontinued breastfeeding and those who were had not been exclusively breast fed for the first six months. According to a study done in western Kenya, children who were introduced to foods early had an increased risk of being underweight [24]. In addition, discontinuation of breastfeeding before two years of age was found to be a significant (P $\$ ).05) risk factor to underweight. In a related study, initiation of breastfeeding after six hours of birth, deprivation from colostrum and improper complementary feeding were found significant (P $₫ 0.05$ ) risk factors for underweight [23].

Failure to initiate breastfeeding within one hour of child birth was found to be a significant ( $\mathrm{P} \unlhd 0.05$ ) risk factor to stunting. Besides, children who were not breastfed within one hour of birth and those who had prelacteal feeds were twice and one and half times respectively, likely to be stunted. None of the breastfeeding practices studied was found to be a significant risk factor to wasting. However, the risk of wasting was 1.5 higher among children who had stopped breastfeeding and those who were on bottle feeding; however, this does not control for age: children who have stopped breastfeeding are older. Similar findings reported no significant association $(\mathrm{P}>0.05)$ between wasting and any infant feeding practice studied [23]. In a study to determine nutrition status of under fives Matee et al, established that breastfeeding was protective against stunting and wasting (odds ratio, 0.8) [25].

In a study in Kampala- Mulago hospital, Owor et al. reported a strong association between severe malnutrition and lack of breastfeeding, an odds ratio 3.222 (P $₫ 0.05$ ) [26]. In a group of severely malnourished only $23 \%$ children aged less than 2 years were still breastfeeding compared to $44 \%$ in the control group. Compliance to the recommended breastfeeding practices allows the child to accrue almost all the benefits of breastfeeding not only in the short run but also in the long term.

\section{CONCLUSION AND RECOMMENDATION}

Overall breastfeeding rates and compliance to most of the recommended breastfeeding practices was high. This could have contributed the acceptable nutrition status among the children. Exclusive breastfeeding for first six months was a rare practice as indicated by early introduction of complementary feeds.

Discontinuation of breastfeeding before the age of twenty four months, lack of EBF for the first six months, bottle feeding and late initiation of breastfeeding are major risk factors to malnutrition among children less than twenty four months of age.

A behaviour change communication (BCC) program should be specifically designed to emphasis on the importance of exclusive breastfeeding for the first six months of age in its contribution to healthy growth and development.

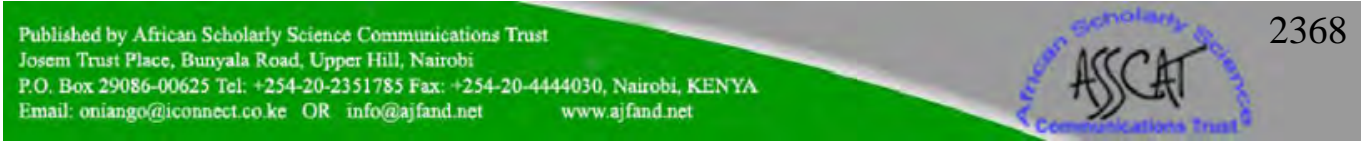




AJFININANE

\section{ACKNOW LEDGEMENT}

We wish to acknowledge Professor E.G. Karuri and Professor W. Kogi- Makau, Dept. of Food Technology and Nutrition, Applied Nutrition Programme, University of Nairobi. Dr. D. Nguku of Nairobi City Council and entire administration and staff of the selected health centres; the University of Nairobi for awarding the scholarship to undertake the study and Miss Marlyn Wairimu and Mr. Melvin Waithaka for patience and inspiration 


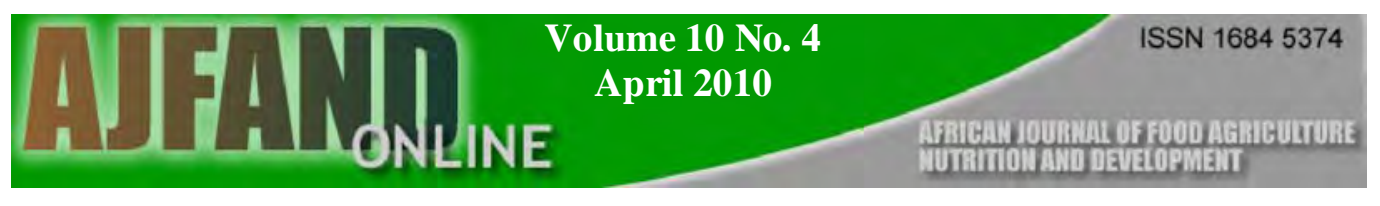

Tablel: Age, sex profiles and feeding modes of the children in percentages

\begin{tabular}{c|cccccc}
\hline $\begin{array}{c}\text { Ages } \\
\text { (months) }\end{array}$ & $\begin{array}{c}\text { Exclusively } \\
\text { breastfeedi } \\
\text { ng (\%) }\end{array}$ & $\begin{array}{c}\text { Started on } \\
\text { Complementar }\end{array}$ & $\begin{array}{c}\text { Continuing } \\
\text { breastfeedi }\end{array}$ & $\begin{array}{c}\text { Not } \\
\text { breastfeedi }\end{array}$ & $\begin{array}{c}\text { Bottle } \\
\text { fed with }\end{array}$ & $\begin{array}{c}\text { Number of } \\
\text { children }\end{array}$ \\
\hline $0-4$ & 38.6 & 61.4 & 99.5 & 0.5 & 31.1 & $205(49 \%)$ \\
$5-6$ & 8.5 & 91.5 & 96.6 & 3.4 & 13 & $59(14.1 \%)$ \\
$7-12$ & 2.9 & 97.1 & 97.3 & 2.7 & 17.7 & $113(27 \%)$ \\
$13-24$ & 0 & 100 & 92.7 & 7.3 & 7.3 & $41 \quad(9.8 \%)$ \\
Male & 20 & 80 & 98.1 & 1.9 & 23.7 & $215(51.9 \%)$ \\
\hline Female & 20.1 & 79.9 & 97.5 & 2.5 & 17.8 & $199(48.1)$ \\
\hline
\end{tabular}

Freq. stands for frequency. 


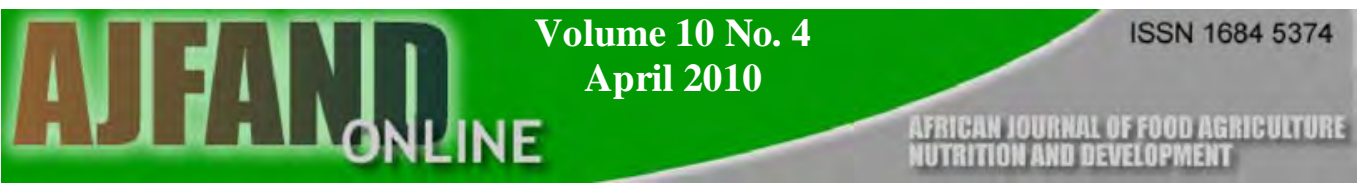

Table 2: $M$ aternal breastfeeding practices

\begin{tabular}{l|cc}
\hline M aternal breastfeeding practices & Appropriate & Inappropriate \\
\cline { 2 - 3 } Ever breastfed the child (n=418) & $99 \%$ & $1 \%$ \\
Initiated breastfeeding within one hour & $61.1 \%$ & $38.9 \%$ \\
of child birth (n=414) & & $21 \%$ \\
Did not give prelacteal feeds (n=414) & $79 \%$ & $9.1 \%$ \\
Breastfed on child demand (n=405) & $90.9 \%$ & $20.9 \%$ \\
Did not use feeding bottles with artificial & $79.1 \%$ & $87.4 \%$ \\
teats in child feeding (n=340) & & \\
Children that EBF for the first six & $12.6 \%$ & $66 \%$ \\
months (n=331) & & $2.2 \%$ \\
Children < than six months EBF (n=235) & $34 \%$ & \\
\hline Continuing breastfeeding (n=414) & $97.8 \%$ & \\
\hline
\end{tabular}




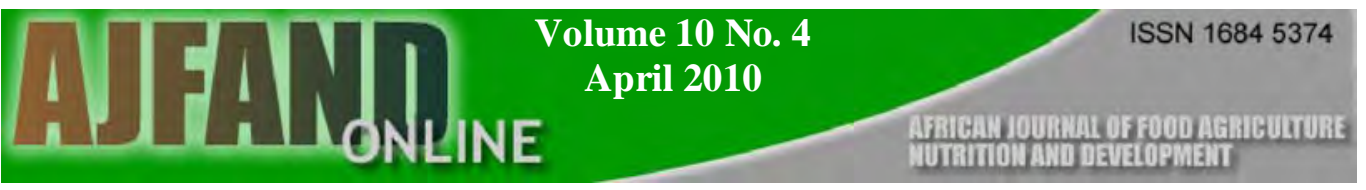

Table 3:Distribution of Study Children by Nutritional Status

\begin{tabular}{l|cccc}
\hline Nutrition Indicators & Male & F emale & Combined & $\begin{array}{c}\text { Normal ranges of } \\
\text { specific status }\end{array}$ \\
\hline Wasting (n=416) & 7 & 2 & $9(2.2 \%)$ & $407(98 \%)$ \\
Severe wasting & - & 1 & $1(0.2 \%)$ & \\
Global underweight $(\mathrm{n}=417)$ & 12 & 14 & $26(6.2 \%)$ & $391(93.8 \%)$ \\
Severe underweight & 3 & 3 & $6(1.4 \%)$ & \\
Stunting n=417) & 26 & 18 & $44(10.6 \%)$ & $373(89.4 \%)$ \\
\hline Severe stunting & 4 & 1 & $5(1.2 \%)$ & \\
\hline
\end{tabular}




AJFIVINANE

Table 4:A ssociation between maternal breastfeeding practices and acute malnutrition among children

\begin{tabular}{|c|c|c|c|c|c|}
\hline $\begin{array}{l}\text { Recommen ded breastfeeding } \\
\text { practices }\end{array}$ & & Normal & Wasting & $\begin{array}{l}\text { Chi- } \\
\text { square }\end{array}$ & Odds Ratio \\
\hline Initiated breastfeeding & Yes & 245 & 6 & 0.128 & 0.8 \\
\hline within one hour of birth & No & 158 & 3 & $\mathrm{p}=0.505$ & CI $(0.2-3.1)$ \\
\hline \multirow[t]{2}{*}{ Gave prelacteal feeds } & No & 317 & 7 & 0.004 & 1.1 \\
\hline & Yes & 86 & 2 & $\mathrm{P}=0.606$ & $\mathrm{CI}(0.2-5.2)$ \\
\hline \multirow[t]{2}{*}{ Breastfed on demand } & Yes & 360 & 8 & 0.041 & 1.2 \\
\hline & No & 35 & 1 & $\mathrm{P}=0.584$ & $\mathrm{CI}(0.2-10.2)$ \\
\hline Used feeding items other & Yes & 262 & 5 & 0.323 & 1.6 \\
\hline than bottles with teats & No & 65 & 2 & $\mathrm{P}=0.57$ & CI $(0.3-8.5)$ \\
\hline EBF for six months/ EBF & Yes & 118 & 4 & 0.9 & 0.5 \\
\hline for child less than six & No & 285 & 5 & $\mathrm{P}=0.343$ & CI (0.1-2.0) \\
\hline \multicolumn{6}{|l|}{ months at time of study } \\
\hline \multirow[t]{2}{*}{ Continuing breastfeeding } & Yes & 394 & 9 & 0.274 & 1.6 \\
\hline & No & 9 & 0 & $P=0.64$ & CI $(0.3-8.2)$ \\
\hline
\end{tabular}




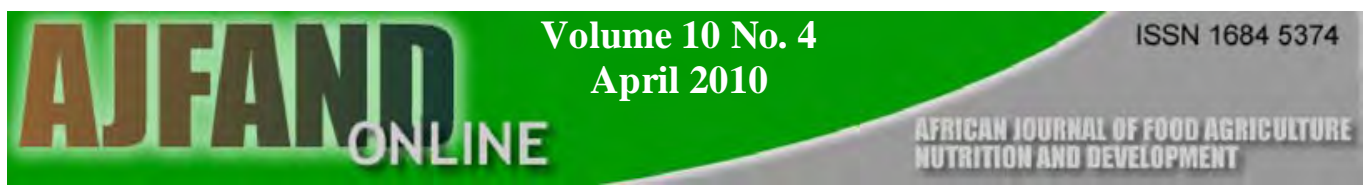

Table 5:A ssociation between maternal breastfeeding practices and underweight among children

\begin{tabular}{|c|c|c|c|c|c|}
\hline \multicolumn{3}{|c|}{ Recommended breastfeeding practices Normal } & \multirow{2}{*}{$\begin{array}{c}\text { Underweight } \\
15\end{array}$} & \multirow{2}{*}{$\begin{array}{l}\begin{array}{l}\text { Chi- } \\
\text { square }\end{array} \\
0.129\end{array}$} & \multirow{2}{*}{$\begin{array}{c}\text { Odds Ratio } \\
1.2\end{array}$} \\
\hline Initiated breastfeeding within & Yes & 237 & & & \\
\hline one hour of birth & No & 150 & 11 & $p=0.72$ & CI $(0.5-2.6)$ \\
\hline \multirow[t]{2}{*}{ Gave prelacteal feeds } & No & 305 & 20 & 0.052 & 1.1 \\
\hline & Yes & 82 & 6 & $p=0.82$ & CI (0.4-2.9) \\
\hline \multirow[t]{2}{*}{ Breastfed on demand } & Yes & 345 & 22 & 0.021 & 0.9 \\
\hline & No & 35 & 2 & $p=0.88$ & CI $(0.2-4.0)$ \\
\hline Used feeding items other than & Yes & 247 & 22 & 1.29 & 0.5 \\
\hline bottles with teats & No & 68 & 3 & $p=0.256$ & CI $(0.1-1.7)$ \\
\hline EBF for six months/ EBF for & Yes & 118 & 4 & 2.83 & 2.5 \\
\hline $\begin{array}{l}\text { child less than six months at } \\
\text { time of study }\end{array}$ & No & 269 & 22 & $p=0.09$ & CI $(0.8-7.3)$ \\
\hline \multirow[t]{2}{*}{ Continuing breastfeeding } & Yes & 380 & 24 & 3.956 & 4.5 \\
\hline & No & 7 & 2 & $p=0.047$ & CI $(0.9-23)$ \\
\hline
\end{tabular}




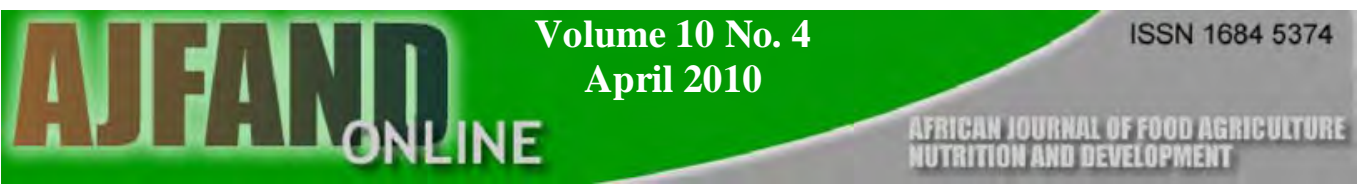

Table 6:Association between maternal breastfeeding practices and stunting among children

\begin{tabular}{|c|c|c|c|c|c|}
\hline \multicolumn{2}{|c|}{ Recommended breastfeeding practices } & \multirow{2}{*}{$\begin{array}{l}\text { Normal } \\
233\end{array}$} & \multirow{2}{*}{$\begin{array}{l}\text { Stunting } \\
19\end{array}$} & \multirow{2}{*}{$\begin{array}{l}\text { Chi- } \\
\text { square }\end{array}$} & \multirow{2}{*}{$\begin{array}{l}\text { Odds Ratio } \\
2.0\end{array}$} \\
\hline Initiated breastfeeding within & Yes & & & & \\
\hline one hour of birth & No & 137 & 24 & $p=0.017$ & CI $(1.1-4.1)$ \\
\hline \multirow[t]{2}{*}{ Gave prelacteal feeds } & No & 294 & 31 & 1.247 & 1.5 \\
\hline & Yes & 76 & 12 & $p=0.264$ & CI $(0.7-3.1)$ \\
\hline \multirow[t]{2}{*}{ Breastfed on demand } & Yes & 329 & 38 & 0.806 & 0.7 \\
\hline & No & 33 & 4 & $p=0.369$ & CI $(0.3-1.6)$ \\
\hline Used feeding items other than & Yes & 236 & 33 & 0.806 & 0.7 \\
\hline bottles with teats & No & 65 & 6 & $p=0.369$ & CI $(0.3-1.6)$ \\
\hline EBF for six months/ EBF for & Yes & 110 & 12 & 0.102 & 1.1 \\
\hline child less than six months at & No & 260 & 31 & $p=0.749$ & CI $(0.6-2.3)$ \\
\hline \multicolumn{6}{|l|}{ time of study } \\
\hline \multirow[t]{2}{*}{ Continuing breastfeeding } & Yes & 362 & 42 & 0.005 & 1.2 \\
\hline & No & 8 & 1 & $p=0.945$ & $\mathrm{CI}(0.1-8.8)$ \\
\hline
\end{tabular}




IJFININANE

\section{REFERENCES}

1. WHO/UNICEF. Global strategy for infant and young child feeding. WHOGeneva. 2003:5-10.

2. $\quad$ K ing F S Helping mothers to breast-feed. Pub. AMREF Nairobi Kenya. 1992; 24-26: 2-3.

3. Central Bureau of Statistics, M inistry of Health, Kenya Demographic Health Survey and ORC Macro Kenya Demographic and Health Survey 2003.Calverton, Maryland.CBS, MoH and ORC Macro. 2004:153-155.

4. UNICEF/Ur D'Urso. Safe motherhood, a newsletter of world Aid activities. 1997:24 (2): 3

5. Royal College of Midwives. Successful breastfeeding. Churcill Livingstone, Mary Law publisher, London. 1991:10.

6. WHO/FAO. Kenya country position paper on nutrition. International Conference on Nutrition (ICN). 1992:12-14.

7. Onayade AA, Abiona TC, Abiyomi 10 and ROA Makanjuola The first six months growth and illness of exclusively and non- exclusively breastfed infants in Nigeria. E. Afri. M ed. J . 2004:Vol. 81(3): 146 -153.

8. ORC Macro Nutrition of young children and mothers in Kenya. Africa Nutrition Chart Books. Maryland, USA. 2004:1,4, 41,43,45.

9. Mirie W Impact of lactation management education on health professionals. $E$. Afri. M ed. J. 2001:Vol. 78(3):128-130.

10. GoK. National development plan (1997-2000), Nairobi: Government printers. 1997.

11. WHO. Measuring change in nutritional status. Geneva. 1983: 63-101.

12. Ngatia EM, Nganga PM, M uita JW G and J K I mungi Dietary Patterns and Nutrition Status of Pre-school children in Nairobi. In the E. Afri. Med. J. 2005:Vol.82 (10):520-525.

13. Banapurmath CR, Nagaraj MC, Banapurmath $\mathrm{S}$ and $\mathrm{N}$ Kesaree Breastfeeding practices in villages of central Karnataka. Indian Ped. J. 1996:Vol.33 (6):477-479.

14. Barton SJ Infant feeding practices of low-income rural mothers. American J of Maternal Child Nursing. 2001:Vol.26 (2):93-97. 
15. Marandi $A$, Afzali $H M$ and $A F$ Hossaini The reasons for early weaning among mothers in Teheran. In the WHO Bulletin. 1993: Vol.71 (5):561-569.

16. USAID. HIV/AIDS: A Guide for Nutritional Care and Support. Food and Nutritional Technical Assistance Project, Academy for Educational Development. Washington DC. 2001:38-41.

17. Torimiro SE, Onayade AA, Olumese I and RO M akanjuola Health benefits of selected global breastfeeding recommendations among children 0-6 months in Nigeria. Nutrition and Health. 2004:Vol. 18(1): 49-59.

18. Shamim S, Jamalvi SW and F Naz Determinants of bottle use amongst economically disadvantaged mothers in Karachi. J Ayub Med Coll Abbottabad. 2006:Vol. 18(1):48-51.

19. Mukuria AG Exclusive breastfeeding and the role of social support and social networks in a low-income urban community in Nairobi Kenya. Ph. D thesis. 1999:96-97, 130.

20. Macharia CW, Kogi-Makau W and NM Murok Dietary intake, feeding and care practices of children in Kathonzweni division, Makueni district, Kenya. E. Afri.Med. J . 2004:Vol. 81(8); 402-407.

21. Mamabolo $R L$, Alberts $M$, M benyane $G X$, Steyn NP, N thangeni NG, Delemarre-Van De Waal HA and NS L evitt Feeding practices and growth of infants from birth to 12 months in the central region of Limpopo province of South Africa. Nutr. J I.2004: Vol. 20(3): 327-333.

22. Kamau-Thuita F, Omwega AM, Muita JWG and UNICEF. Childcare practices and Nutrition status of children aged 0-2 years in Thika, Kenya. E. Afri. M ed. J. 2002:Vol. 79(10): 524-529.

23. Kumar D, Goel N K, Mittal PC and P Misra Influence of infant-feeding practices on nutritional status of under-five children. Indian J. of Paediatrics. 2006:Vol.73 (5): 417-421.

24. Bloss E, Wainaina F and RC Bailey Prevalence and predictors of underweight, stunting, and wasting among children aged 5 and under in western Kenya. J . of trop. Paediatrics. 2004:Vol. 50(5):260-270.

25. M atee $M I, M$ sengi $A E$, Simon $E$, lyamuya $E F, M$ winula J $H, M$ bena $E C$, Samaranayake LP and F Scheutz Nutritional status of under fives attending maternal and child health clinics in Dar es Salaam, Tanzania. E Afr. Med. J. 1997:Vol. 74(6):368-371. 


AIFANINANE

26. Owor M, Tumwine JK and JK Kaukauna Socio-economic risk factors for severe protein energy malnutrition among children in Mulago Hospital, Kampala. E.Afr.M e. J. 2000:Vol. 77(9): 471-474. 